Article

\title{
Comparative Transcriptome Analysis of Pine Trees Treated with Resistance-Inducing Substances against the Nematode Bursaphelenchus xylophilus
}

\author{
Jungwook Park ${ }^{1,2,+}+$, , Hee Won Jeon ${ }^{3,+}{ }^{,}$Hyejung Jung ${ }^{1}$, Hyun-Hee Lee ${ }^{1}$, Junheon Kim ${ }^{4}(\mathbb{D}$, \\ Ae Ran Park ${ }^{3}$, Namgyu Kim ${ }^{1}$, Gil Han ${ }^{1}$, Jin-Cheol Kim ${ }^{3, *(D)}$ and Young-Su Seo ${ }^{1, *}$ \\ 1 Department of Integrated Biological Science, Pusan National University, Busan 46241, Korea; \\ jjuwoogi@pusan.ac.kr (J.P.); jhj4059@pusan.ac.kr (H.J.); ehyuna92@pusan.ac.kr (H.-H.L.); \\ titanic622@pusan.ac.kr (N.K.); croone@pusan.ac.kr (G.H.) \\ 2 Environmental Microbiology Research Team, Nakdonggang National Institute of Biological \\ Resources (NNIBR), Sangju 37242, Korea \\ 3 Department of Agricultural Chemistry, Institute of Environmentally Friendly Agriculture, College of \\ Agriculture and Life Sciences, Chonnam National University, Gwangju 61186, Korea; \\ jeon-hw@naver.com (H.W.J.); arpark9@naver.com (A.R.P.) \\ 4 Forest Insect Pests and Diseases Division, National Institute of Forest Science, Seoul 02455, Korea; \\ junheonkim@korea.kr \\ * Correspondence: kjinc@chonnam.ac.kr (J.-C.K.); yseo2011@pusan.ac.kr (Y.-S.S.) \\ + These authors contributed equally to this work.
}

Received: 17 July 2020; Accepted: 24 August 2020; Published: 26 August 2020

Abstract: The pinewood nematode (PWN) Bursaphelenchus xylophilus causes pine wilt disease, which results in substantial economic and environmental losses across pine forests worldwide. Although systemic acquired resistance (SAR) is effective in controlling PWN, the detailed mechanisms underlying the resistance to PWN are unclear. Here, we treated pine samples with two SAR elicitors, acibenzolar-S-methyl (ASM) and methyl salicylic acid (MeSA) and constructed an in vivo transcriptome of PWN-infected pines under SAR conditions. A total of 252 million clean reads were obtained and mapped onto the reference genome. Compared with untreated pines, 1091 and 1139 genes were differentially upregulated following the ASM and MeSA treatments, respectively. Among these, 650 genes showed co-expression patterns in response to both SAR elicitors. Analysis of these patterns indicated a functional linkage among photorespiration, peroxisome, and glycine metabolism, which may play a protective role against PWN infection-induced oxidative stress. Further, the biosynthesis of flavonoids, known to directly control parasitic nematodes, was commonly upregulated under SAR conditions. The ASM- and MeSA-specific expression patterns revealed functional branches for myricetin and quercetin production in flavonol biosynthesis. This study will enhance the understanding of the dynamic interactions between pine hosts and PWN under SAR conditions.

Keywords: comparative transcriptome; pine wilt disease; Bursaphelenchus xylophilus; Pinus densiflora; systemic acquired resistance (SAR); acibenzolar-S-methyl (ASM); methyl salicylic acid (MeSA)

\section{Introduction}

Pine trees from the genus Pinus are widely distributed in a variety of environments, ranging from areas at sea level to mountainous areas and from some of the coldest to the hottest environments on earth [1-3]. Pine forests are among the most valuable resources, with respect to timber, fuel, and various wood products [4-6]; native pine forests also provide important habitats or source of 
food for numerous species of birds and mammals in natural ecosystems. However, in recent decades, pine trees have suffered from epidemic attacks of pine wilt disease (PWD), and their populations have reduced markedly since the 1960s [7,8]. PWD, caused by the pinewood nematode (PWN) Bursaphelenchus xylophilus, is an extremely destructive disease that affects pine forests and results in substantial economic and environmental losses on a worldwide scale. Subsequent to its initial detection in Japan at the beginning of the 20th century [9], PWD spread rapidly throughout a number of East Asian countries, notably, China, Korea, and Taiwan, and thereafter extended to Europe (Portugal and Spain) [10-13]. In Japan, some 700,000 $\mathrm{m}^{3}$ of pine forests are infected by PWD each year [14], whereas in the 10 years between 2003 and 2013, China lost USD 20 billion as a consequence of the mass dieback of 1 million ha of pine forests in 16 provinces [15].

B. xylophilus has the unique capacity to feed on both living trees and fungi $[16,17]$. Moreover, it is known to be vectored by pine sawyers of the genus Monochamus and is transmitted from deceased to healthy pine trees during the summer period of oviposition [18,19]. The PWN feeds on epithelial cells in the resin canals of host trees and subsequently migrates through surrounding tissues to kill parenchymal cells [20-22]. Populations of infesting PWN undergo rapid expansion, and in the process cause extensive destruction of xylem tissues, thereby interrupting water and resin flow in host trees. By autumn, the trees have usually succumbed to the detrimental effects of the infection [18,19]. The reiteration of infection and the pathogenic cycle ensures that the PWN is readily disseminated throughout pine forests.

Owing to the serious threat posed by PWN, considerable effort has been expended in attempts to control the disease. Control methods are based primarily on aerial and ground applications of conventional insecticides (fenitrothion and thiacloprid) to kill the pine sawyer vectors, or involve the injection of trees with nematicides, such as levamisole hydrochloride, morantel tartrate, and emamectin benzoate [23-25]. Recently, however, there has been growing public concerns regarding the use of pesticides and nematicides, on account of their detrimental effects on the environment and human health, as well as undesirable effects on non-target organisms [23,26]. In this regard, the establishment of systemic acquired resistance (SAR) in pine trees may provide a viable alternative that can overcome the problems associated with the currently used control agents. SAR is a highly enhanced immune-type plant resistance that confers long-term broad-spectrum resistance against a diverse range of invaders [27-30]. Prophylactic induction of SAR prior to contact with nematodes enables pine trees to mount a more effective resistance against PWD [8,31]. SAR can be induced not only by exposure of plants to abiotic and biotic stresses but also by using synthetic resistance-inducing substances (RISs) [32]. Among the commonly employed RISs, salicylic acid (SA) is an endogenous signalling compound that regulates the induction of SAR, as well as plant growth and development [3335]. Although the efficacy of SAR has been well validated, numerous details remain unclear, notably, the identity of the genetic elements activated by RISs, and specifically in the case of PWD, how to effectively exploit SAR to protect pine trees from PWN infestation.

Gaining an understanding of the mechanisms underlying resistance to PWD is a complex issue and demands integrated management, as studies that focus exclusively on isolated elements of the host-pathogen system (i.e., host plant, SAR, or the causal nematode) fail to fully reflect the dynamic interactions among these key elements. Ideally, in vivo studies on PWN-infected pine trees under conditions of induced SAR are the optimal approach for addressing this problem. In this regard, recent advances in high-throughput sequencing have enabled unbiased and more accurate quantification of transcripts at a high resolution to determine genome-wide expression profiles in organisms under specified conditions [36]. In vivo transcriptome analyses have made it possible to trace the cascades of biological systems that are triggered in response to invaders, and to identify key defence-related functions in plant-nematode interactions [37,38]. Furthermore, comparison between different in vivo transcriptomes has enabled us to assess the fundamental principles of plant resistance against pathogens, as well as the specific effects of the gene expression patterns uniquely induced under each condition [39-41]. 
In this study, we examined the effects of two SA-derived SAR elicitors, acibenzolar-S-methyl (ASM) and methyl salicylic acid (MeSA), which effectively inhibited disease symptoms in PWN-infected pine trees. After treatment with these elicitors, the in vivo differentially expressed genes (DEGs) were characterised in B. xylophilus-infected pine trees. Compared to control samples that were not treated with elicitors, DEGs reflected both the stressful conditions under highly diseased symptoms and the defence response against nematode infection. A comparative analysis of these in vivo transcriptomes revealed that co-expression patterns among upregulated DEGs constitute major biological systems in pine trees. Furthermore, by performing network analysis based on protein-protein interactions, we validated key functions, including photorespiration and flavonoid biosynthesis, which may play a critical role in the inhibition of, and protection against, PWN. In addition, we conducted functional enrichment analysis of unique expression patterns to elucidate the ASM- and MeSA-specific reactions and outputs that comprise the defence mechanisms of pine trees. Collectively, the findings of this study provide new insights into the positive roles of RISs during PWD development and contribute to enhancing general understanding of the interactions between host pine trees and PWN.

\section{Materials and Methods}

\subsection{PWN Source}

The causal agent of PWD, the PWN B. xylophilus, was obtained from the National Institute of Forest Science (NIFoS: Seoul, Korea). B. xylophilus was isolated from the infected tissues of red pine (Pinus densiflora) and is highly virulent to genus Pinus trees [42,43]. For all experiments, PWN was cultured on the hyphae of the fungus Botrytis cinerea grown on potato dextrose agar medium (PDA) at $25{ }^{\circ} \mathrm{C}$ for 1 week. Cultured PWN was separated from the PDA medium using the Baermann funnel technique [44]. A suspension of PWN in distilled water was adjusted to a concentration of approximately 20,000 nematodes/mL.

\subsection{Preparation of Chemical Formulations}

ASM (>99.4\% purity) was kindly supplied by Syngenta Korea (Seoul, Korea). A suspension concentrate-type formulation of ASM was prepared by mixing 5.03\% (w/w) ASM, 2\% (w/w) CR-KSP40M (the mixture of ethoxylated tristyrylphenol phosphate, potassium salt, and propylene glycol) as a wetting and dispersing agent, $10 \%(w / w)$ propylene glycol as an antifreeze agent, $0.1 \%(w / w)$ xanthan gum as a viscosity modifier, $0.1 \%(w / w)$ 1,2-Benzisothiazolin-3-one as a preservative, $0.1 \%(w / w)$ polydimethylsiloxane as a defoamer, and $82.67 \%(w / w)$ water. MeSA ( $>99.0 \%$ purity) was purchased from Tokyo Chemical Industry Co., Ltd. (Tokyo, Japan), an emulsifiable concentrate-type formulation which was prepared by mixing $20 \%(w / w)$ MeSA, $20 \%(w / w)$ propylene glycol mono-methyl ether as a solubilizer, $20 \%(w / w)$ CR-MOC25 (the mixture of ethoxylated castor oil, calcium dodecylbenzenesulfonate, and tristyrylphenol ethoxylates) as an emulsifier, and $40 \%(w / w)$ methylated soybean oil as a diluent.

\subsection{In Vivo Pine Seedling Assay}

For use in in vivo assays, P. densiflora seedlings ( 3 years old) were purchased from Daelim seedling farm (Okcheon, Korea), and maintained under a relative humidity of $70 \%$. ASM and MeSA preparations were dissolved in water at an active concentration of $1600 \mu \mathrm{g} / \mathrm{mL}$, of which $5 \mathrm{~mL}$ was subsequently sprayed onto the pine seedlings, with the treatment being conducted twice at 1-week intervals. Distilled water containing $250 \mu \mathrm{g} / \mathrm{mL}$ Tween 20 was used as an untreated negative control. One week after treatment, the pine seedlings were inoculated with PWN. Briefly, after making a small slit with a surface-sterilised knife, a small piece of absorbent cotton was embedded into the slit, and $100 \mu \mathrm{L}$ of PWN suspension was pipetted onto the absorbent cotton. The inoculation sites were then covered with the parafilm (Heathrow Scientific, Vernon Hills, IL, USA) to prevent desiccation. Each treatment was replicated four times and each experiment was conducted twice. At 30 days after PWN 
inoculation, PWD was evaluated with reference to a numerical scale from 0 to 5 , where $0=$ healthy seedlings with normal green needles; $1=1-20 \%$ discoloured (brown) needles; $2=21-40 \%$ brown needles; $3=41-60 \%$ brown needles; $4=61-80 \%$ brown needles with bending of the terminal shoots of seedlings; $5=81-100 \%$ brown needles and wilting of the entire seedling. Disease severity was determined as follows: disease degree $=\sum$ (number of samples per score $\times$ score)/total number of needles. Pine seedlings that were not inoculated with PWN served as the positive controls.

\subsection{RNA Isolation}

Pinus tree RNAs for in vivo transcriptome analysis were extracted from samples obtained from plants used in the pine seedling assay. Pine samples were surface sterilised with $70 \%$ ethanol and then rinsed with distilled water. Plant RNAs were isolated using a modified hexadecyltrimethylammonium bromide (CTAB) method [45]. One gram of needles was ground in liquid nitrogen and mixed with $15 \mathrm{~mL}$ of extraction buffer containing $100 \mathrm{mM}$ Tris- $\mathrm{HCl}(\mathrm{pH} 8), 2 \% \mathrm{CTAB}$, $30 \mathrm{mM}$ ethylenediaminetetraacetic acid, $2 \mathrm{M} \mathrm{NaCl}, 0.05 \%$ spermidine, $2 \%$ polyvinylpolypyrrolidinone, $2 \%$-mercaptoethanol, and $1.5 \mathrm{mg} / \mathrm{mL}$ proteinase $\mathrm{K}$. The suspension was incubated at $42{ }^{\circ} \mathrm{C}$ for $90 \mathrm{~min}$ and then extracted with $15 \mathrm{~mL}$ chloroform-isoamyl alcohol (24:1). Total RNAs were precipitated with $10 \mathrm{M} \mathrm{LiCl}$. After washing with $70 \%$ ethanol, the RNA pellets were dissolved in diethylpyrocarbonate-treated water, and RNA quality was evaluated using gel electrophoresis and a NanoDrop2000 spectrophotometer (Thermo Scientific, Barrington, IL, USA).

\subsection{RNA Sequencing}

An Agilent 2100 Bioanalyzer (Agilent Technologies, Santa Clara, CA, USA) was used to assess RNA integrity. Total RNAs were converted to cDNA libraries using a TruSeq RNA Sample Preparation Kit (Illumina, San Diego, CA, USA). Briefly, $1 \mu \mathrm{g}$ of total RNAs was enriched for mRNA using oligo-dT coated magnetic beads, fragmented, and reverse transcribed into cDNAs. The cDNA libraries were sequenced using an HiSeq 2000 sequencing platform (Illumina), according to the manufacturer's instructions, by Macrogen (Seoul, Korea). RNA-seq libraries comprising sequences with 101-bp read lengths were constructed using the paired-end strategy. The quality of raw reads was evaluated using the FastQC tool [46]. All raw sequencing data presented in this study have been deposited in the National Center for Biotechnology Information Gene Expression Omnibus database under accession no. GSE154134.

\subsection{Genome Characterization}

The reference genome sequence for loblolly pines from the genus Pinus was downloaded from the PineRefSeq database [47], and the gene information used for transcriptome analyses was derived via v2.01 annotation [48]. Genes, exons, and coding sequences were defined in the downloaded GTF file. Duplicate gene information predicted using the annotation tools Augustus, GenomeThreader, and Gmap was filtered using an in-house-developed Python script.

\subsection{Transcriptome Analysis}

Raw reads in the FASTQ format were filtered using the FASTX-Toolkit [49] to remove sequences with low-quality scores (50\% of the sequence with a Phred score $\geq 28$ ). An in-house Python script was used to synchronise the forward and reverse directions of the filtered reads. Pre-processed reads were aligned to the reference genome sequence using the Burrows-Wheeler Aligner (BWA) based on the maximal exact matches algorithm [50]. SAMtools was used to convert SAM files containing mapping results to binary format BAM files, and subsequently we sorted these according to genomic positions [51]. Mapped reads per coding sequence in Pinus trees were counted using the FeatureCounts module in the Subread package [52]. To quantify gene transcription levels, we determined relative transcript abundance using the reads per kilobase per million mapped reads (RPKM) method [53]. 


\subsection{DEG Analysis}

Analyses of the ASM- and MeSA-specific DEGs were performed using the DEGseq package in the R statistical environment [54]. In this statistical package, MARS with a random sampling model is widely used to detect and visualise the intensity-dependent ratio of transcriptome data [55]. As input data, we used the RPKM values of each gene, and thereafter examined the effects of the two RISs on genome-wide gene expressions compared with the untreated controls. For multiple testing corrections, $p$-values calculated for each gene were adjusted to false discovery rate (FDR) values using the Benjamini-Hochberg procedure [56]. The criteria set to indicate a significant difference in expression were as follows: $\mid \log _{2}$-fold change $\mid \geq 1$ and FDR $<0.05$. The functional characterisation of all DEGs was performed using the BlastKOALA tool, selecting the eukaryotes taxonomy group [57]. On the basis of the identified Kyoto Encyclopedia of Genes and Genomes (KEGG) ortholog groups of each DEG, we constructed BRITE functional hierarchies and KEGG pathways.

\subsection{Comparative Transcriptome and Functional Enrichment}

For a comparative study of the transcriptomes obtained following the ASM and MeSA treatments, we implemented the VennDiagram package in the R environment, which can depict the co-expression and unique groups of upregulated DEGs.

On the basis of the KEGG pathway and gene ontology (GO) terms, we performed functional enrichment analyses to identify the significantly activated systems in the co-expression and unique patterns. KEGG and GO information for all pine genes were obtained from the annotation file of the PineRefSeq database. We assessed the scale of upregulated DEGs for each system, and the hypergeometric distribution was used to identify significantly enriched systems using the phyper function in R [58]. The parameters used in this analysis were as follows: $N$, the number of genes annotated to KEGG and GO information; $n$, the number of DEGs of $N$; $M$, the number of genes annotated to a specific system; $m$, the number of DEGs of $M$. An FDR value $\leq 0.05$ was considered to be indicative of a significant difference. To enhance system stability, results with less than five genes were filtered out. Network structures of functional systems of interest were also constructed using the Cytoscape tool [59].

\subsection{Protein-Protein Interaction Network Analysis}

The upregulated DEGs associated with the co-expression patterns derived from comparative transcriptome analysis were used as input data for the Search Tool for the Retrieval of Interacting Genes/Proteins (STRING) database [60]. STRING v11 contains 24,584,628 proteins from 5090 organisms and facilitates assessments of functional interactions, including all types of direct and indirect associations. For the purpose of this analysis, we selected Tracheophyta, as the higher taxonomic level, as the background source. The minimum required score for each interaction was customised at a confidence criterion of 0.50 .

\subsection{Quantitative Real-Time PCR (qPCR) Analysis}

Total RNAs were extracted from the pine samples under the same conditions as the in vivo transcriptome analysis. First-strand cDNA was synthesised by using SuperiorScript ${ }^{\mathrm{TM}}$ III cDNA Synthesis Kit (Enzynomics, Daejeon, Korea) with oligo-dT primers in accordance with the manufacturer's protocol. Several genes belonging to major systems in co-expression patterns were subjected to qPCR with specific primers (Table S1). qPCR analysis was performed with TOPreal ${ }^{\mathrm{TM}}$ qPCR 2X PreMix (SYBR Green with low ROX) (Enzynomics) on a Rotor-gene Q (Qiagen, Valencia, CA, USA). Relative expression levels were calculated using the comparative $2^{-\Delta \Delta \mathrm{CT}}$ method with elongation factor (PITA_47202) as the internal control. The qPCR results are shown as the means \pm SD of three independent biological replicates. 


\section{Results}

\subsection{Inhibitory Effects of the ASM and MeSA Treatments against PWN Infection}

Inhibitory activity under conditions of SAR induction was assessed during the development of PWD. Following the treatment of 3-year-old pine seedlings with either ASM or MeSA, the severity of disease (as ascertained by needle discolouration) caused by B. xylophilus was evaluated (Figure 1). On day 30 after treatment, untreated pine seedlings showed an infection rate of 100\%, with a disease severity score of 5 . In contrast, seedlings treated with RISs showed substantially fewer PWD-related symptoms, with most needles remaining healthy with the absence of brown discolouration, and overall disease severity being scored as 0.75 (an average infection rate of 15\%). All seedlings that received no PWN inoculation remained healthy. These results accordingly indicated that ASM- and MeSA-induced SAR were effective in activating defence mechanisms against PWD.

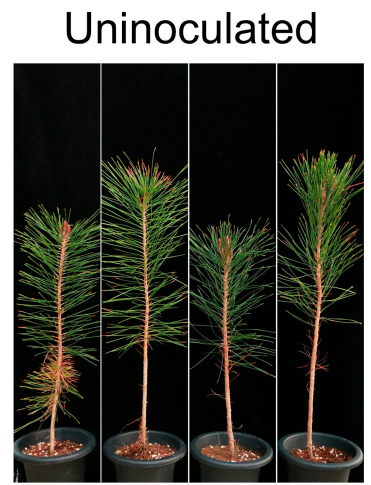

0

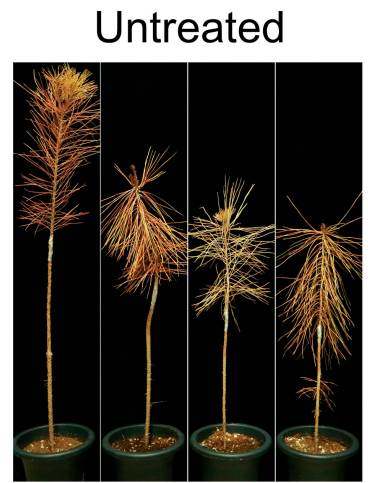

5

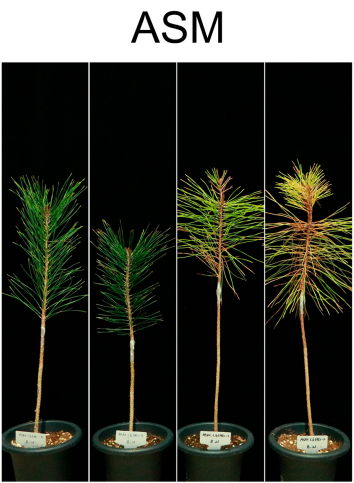

0.75

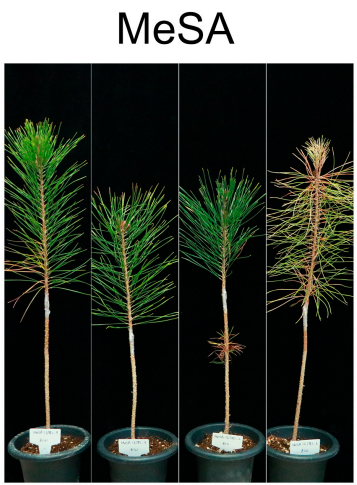

0.75

Figure 1. The influence of acibenzolar-S-methyl (ASM) and methyl salicylic acid (MeSA) on pine wilt disease (PWD) resistance. Photographs of pine seedling inoculated with the nematode B. xylophilus were taken at 30 days after resistance-inducing substance treatment. PWD severity was scored for needle discolouration on a scale of 0 to 5 . The numbers below the photographs denote the mean severity scores determined from four seedlings per treatment. Uninoculated seedlings served as positive controls, and untreated seedlings, as negative controls.

\subsection{Overview of the In Vivo Transcriptomes in PWN-Infected Pine Trees}

After identifying the positive effects of ASM and MeSA with regard to resistance against $B$. xylophilus infection (Figure 1), an in vivo transcriptome analysis of pine trees was performed using RNA-seq technology. SAR was induced in pine seedlings via treatment with ASM and MeSA, and thereafter PWN-infected seedlings were harvested to extract in vivo total RNAs. Pines treated with distilled water containing Tween 20 (untreated sample) were used as negative controls. From a total of nine RNA-seq libraries with three replicates, approximately 294 million paired-end reads were generated, yielding an average of 32 million reads per library (Table 1). Most reads were of good quality with an average Phred score of 40 (Figure S1). After quality filtering, a total of 288 million reads $(98.0 \%)$ remained (Table S2). A reference genome sequence for the genus Pinus was previously reported by Zimin et al. [48], the 22,103,635,615-bp assembly of which has a GC content of 34.8\% and 47,602 computationally predicted genes, among which, 45,528 are non-redundant genes (Table S3). The filtered reads were mapped onto the reference genome sequences using BWA tool [50], with an average of $89.2 \%$ (ranging from $23,843,785$ to $30,506,098$ ) of all reads being successfully mapped (Table S2). 
Table 1. Detailed information of the RNA-seq libraries.

\begin{tabular}{clcccc}
\hline Sample & Read Type & GC (\%) & Quality $^{\mathbf{1}}$ & Total Reads & Total Length (bp) \\
\hline ASM_1 & Paired end & 47 & 40 & $27,814,772$ & $2,805,933,290$ \\
ASM_2 & Paired end & 45 & 40 & $35,228,444$ & $3,554,276,515$ \\
ASM_3 & Paired end & 46 & 40 & $33,425,670$ & $3,372,510,853$ \\
MeSA_1 & Paired end & 45 & 40 & $31,973,654$ & $3,226,375,119$ \\
MeSA_2 & Paired end & 45 & 40 & $33,377,584$ & $3,367,938,501$ \\
MeSA_3 & Paired end & 46 & 40 & $33,589,898$ & $3,389,002,001$ \\
Untreated_1 & Paired end & 45 & 40 & $31,763,374$ & $3,205,080,196$ \\
Untreated_2 & Paired end & 46 & 40 & $33,120,212$ & $3,341,300,502$ \\
Untreated_3 & Paired end & 45 & 40 & $34,069,162$ & $3,437,840,259$ \\
\hline
\end{tabular}

${ }^{1}$ Average Phred quality score.

\subsection{Genes Induced by PWN Infection under SAR Induction}

During the course of PWD development in pine trees, changes in genome-wide gene expressions in response to treatment with RISs were investigated. The 45,528 non-redundant genes were analysed by applying $\mid \log _{2}$-fold change (RIS sample/untreated sample) $\mid \geq 1$ and FDR $<0.05$ as cut-off criteria (Figure 2a,b). In scatter plots and M (log ratio) against A (mean average) scales (MA-plots), each point represents a single pine gene. We compared the expression level of each gene in the untreated sample with that in ASM and MeSA treatment samples. In the MA-plots, red points indicated candidates that have an FDR value $<0.05$. All DEGs in each of the two RIS treatments are listed in Table S4. In response to ASM treatment, 1915 genes were differentially expressed during PWN infection (Figure 2c and Table S4), among which, 1091 (57.0\%) were upregulated and 824 (43.0\%) were downregulated, whereas in seedlings treated with MeSA, there were 1139 (60.6\%) upregulated and $742(39.4 \%)$ downregulated DEGs (Figure $2 \mathrm{c}$ and Table S4). Since the major physiological activity would have been inactivated in the stressful conditions of the untreated samples, it seems that a relatively large number of genes were distributed with upregulation changes.

It was confirmed that the DEGs induced by the two RISs are distributed in the same major functional hierarchies, although the orders differed. In the donut charts depicted in Figure 2c, the outer rings show the top five functional categories and their respective proportions. DEGs encoding carbohydrate metabolism comprised the largest functional category in both ASM (123 genes, 16.0\%) and MeSA (131 genes, 17.6\%) treatments. Other major categories included are as follows: biosynthesis of other secondary metabolites ( 85 and 66 genes in the ASM and MeSA treatments, respectively); lipid metabolism (67 and 53 genes); protein families: genetic information processing (65 and 61 genes); protein families: signalling and cellular processes (58 and 70 genes). These findings revealed that the genetic elements in the pine genome induced by the two RISs for defence against PWN tend to be quantitatively and functionally similar. 
(a)
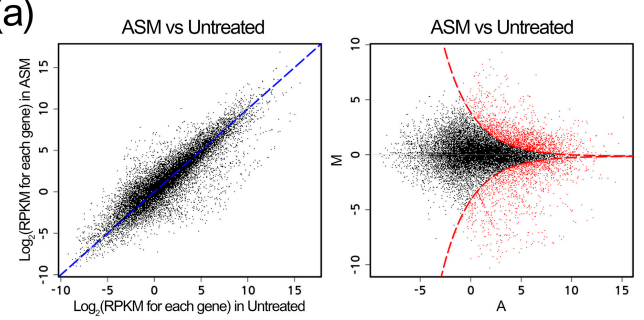

(b)

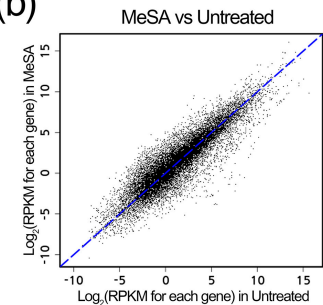

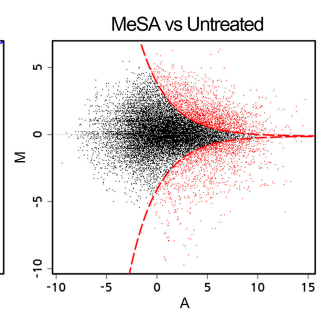

(c)
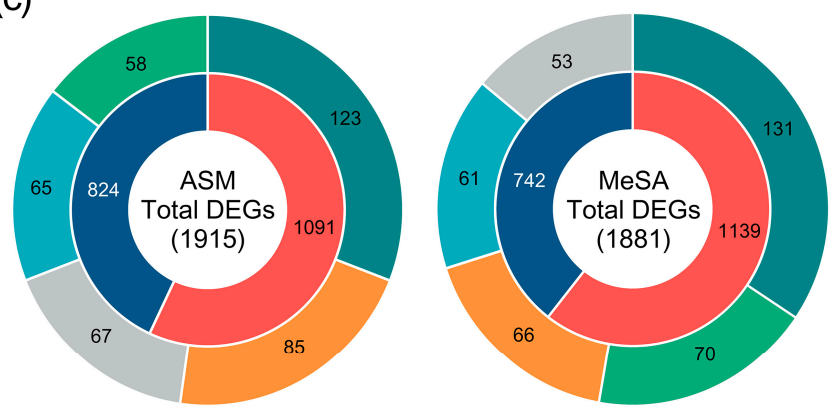

$\square$ Upregulated DEGs

Downregulated DEGs

Carbohydrate metabolism

Biosynthesis of other secondary metabolites

$\square$ Lipid metabolism

$\square$ Protein families: genetic information processing

$\square$ Protein families: signaling and cellular processes

Figure 2. Overview of the differentially expressed genes (DEGs) in acibenzolar-S-methyl (ASM) and methyl salicylic acid (MeSA) treatments. Differential expression was analysed using scatter plots and $\mathrm{M}$ (log ratio) against A (mean average) scales (MA-plots) in the DEGseq package. Each point represents one of 45,528 non-redundant genes in pine trees. (a) Comparison of the ASM-treated and untreated samples. The scatter plot depicts differences in gene expression between the two groups after normalisation. Genes showing significant differences in expression are indicated by red colour in the MA-plot (false discovery rate, FDR < 0.05). (b) Comparison of the MeSA-treated and untreated samples. (c) Donut charts illustrating the distribution of DEGs and functional hierarchies. The inner layer shows the distribution of upregulated and downregulated DEGs, and the outer layer comprises the top five functional categories. The size of ring segments is indicative of the relative proportion of DEGs in each category.

\subsection{Common Systems Activated by the RISs for Response to PWN Infection}

To examine the characteristics of the SAR (induced by the ASM and MeSA treatments) with respect to defence mechanisms, upregulated DEGs were assessed and a comparative transcriptome map consisting of co-expression and unique expression patterns was constructed. The majority (650 genes) of upregulated DEGs were observed to be commonly expressed in response to both ASM (59.6\% of the total) and MeSA (57.1\%) treatments (Figure 3a). In addition, 441 and 489 genes were found to be uniquely expressed in response to the ASM and MeSA treatments, respectively (Figure 3a). On the basis of BRITE hierarchy analysis, it was found that genes showing co-expression patterns are associated with major biological functions involved in metabolic and signalling processes in pine trees (Figure S2). In contrast, among the DEGs showing a unique expression pattern, the unclassified metabolism category, the molecular relationships of which are unknown [57], accounted for a relatively higher distribution (9.5\% and $12.1 \%$ following the ASM and MeSA treatments, respectively) than in DEGs showing co-expression patterns. The high proportion and clear function of DEGs showing co-expression patterns under both SAR conditions are indicative of a tendency towards a fundamental defence strategy against PWN infection.

In the further analysis of the two in vivo transcriptomes, DEGs were functionally analysed with reference to the KEGG pathway database, and 161 and 139 pathways in KEGG were assigned to upregulated DEGs in ASM and MeSA treatments, respectively. In line with expectations, DEGs showing co-expression patterns were found to be associated with a wide range of metabolic pathways, among which, 11 pathways were significantly enriched with hypergeometric distribution (FDR value $<0.05$ ) (Figure 3b). Photosynthesis-antenna proteins (ko00196, 6 genes), porphyrin and chlorophyll metabolism (ko00860, 14 genes), glyoxylate and dicarboxylate metabolism (ko00630, 13 genes), carbon fixation 
in photosynthetic organisms (ko00710, 11 genes), and glycine, serine, and threonine metabolism (ko00260, 12 genes) were the major common pathways activated by ASM and MeSA treatments. In addition, the following secondary metabolite-related pathways were found to be highly enriched: metabolism of xenobiotics by cytochrome P450 (ko00980, 14 genes); drug metabolism-cytochrome P450 (ko00982, 14 genes); stilbenoid, diarylheptanoid, and gingerol biosynthesis (ko00945, 6 genes); flavonoid biosynthesis (ko00941, 11 genes).

(a)

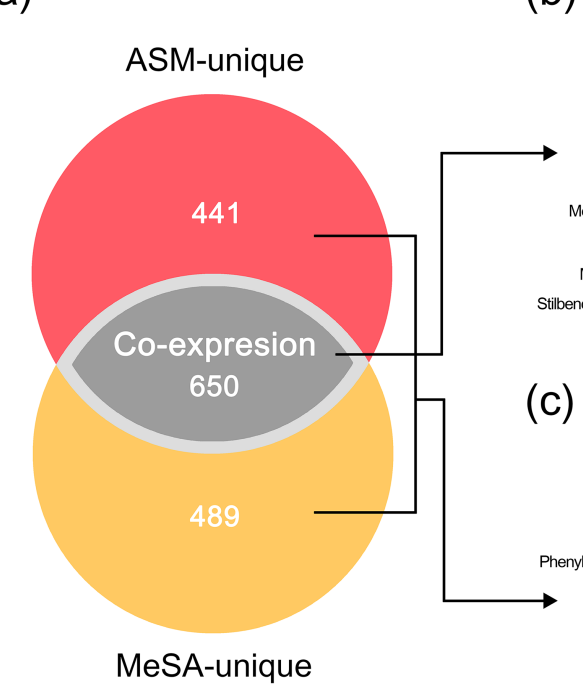

(b)

c)
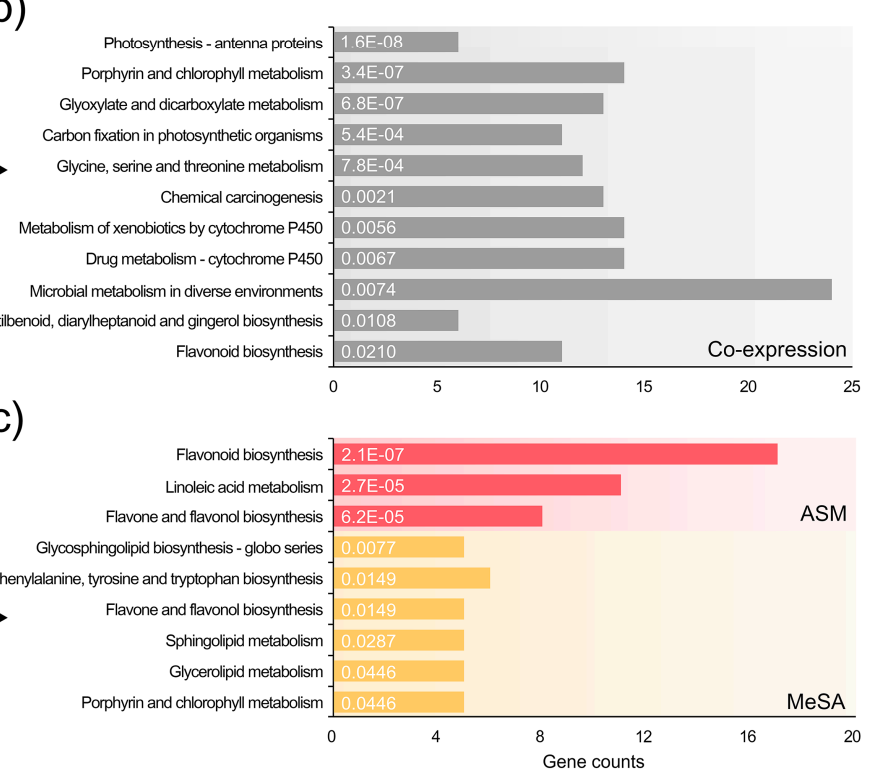

Figure 3. Comparative in vivo transcriptomes of upregulated differentially expressed genes (DEGs) and Kyoto Encyclopedia of Genes and Genomes (KEGG) pathway enrichment in acibenzolar-S-methyl (ASM) and methyl salicylic acid (MeSA) treatment groups. (a) A Venn diagram showing the co-expression and unique expression groups of upregulated DEGs. Comparative analysis revealed 650 overlapping DEGs. A further 441 and 489 DEGs were identified as being uniquely expressed in response to the ASM and MeSA treatments, respectively. (b) Significantly enriched KEGG pathways for the co-expression group. Significant pathways were identified and ranked based on hypergeometric distribution with an FDR $<0.05$. The length of bars indicates the number of DEGs in each KEGG pathway. (c) Significantly enriched KEGG pathways for ASM- and MeSA-specific patterns.

Subsequently, the upregulated DEGs showing co-expression patterns were examined to determine significant genetic interactions based on direct and indirect protein-protein associations [60]. In this regard, interaction network maps can make a valuable contribution in gaining a further understanding of the functioning flow of biological systems under conditions of SAR induction. At an interaction cut-off value of 0.5 , a total of 561 upregulated DEGs with 409 protein nodes were extracted. After removing non-interacting genes, 175 protein nodes were included in the final network, which consisted of 386 interactions (Figure 4a). Overlaying the functional KEGG information onto the interaction network map revealed a densely connected subnetwork comprising major pathways that are highly enriched in DEGs showing co-expression patterns (Figure 3b). This subnetwork comprised genes associated with photosynthesis-antenna proteins (5 nodes), carbon fixation in photosynthetic organisms (7 nodes), glyoxylate and dicarboxylate metabolism (9 nodes), glycine, serine, and threonine metabolism (6 nodes), and peroxisome (4 nodes). As shown in Figure $4 \mathrm{~b}$, glyoxylate and dicarboxylate metabolism in photosynthetic organisms are positioned in the centre of the subnetwork, connected to each of the other three pathways. Among these, PITA_09445 (sedoheptulose-1,7-bisphosphatase) of carbon fixation in photosynthetic organisms showed the highest node degree with 11 interactions. It was also found that PITA_31477, encoding glutamate-glyoxylate aminotransferase 2, and PITA_33653, encoding serine-glyoxylate aminotransferase, occupy critical hub positions associated with the carbon fixation in 
photosynthetic organisms; glyoxylate and dicarboxylate metabolism; glycine, serine, and threonine metabolism; peroxisome.

(a)

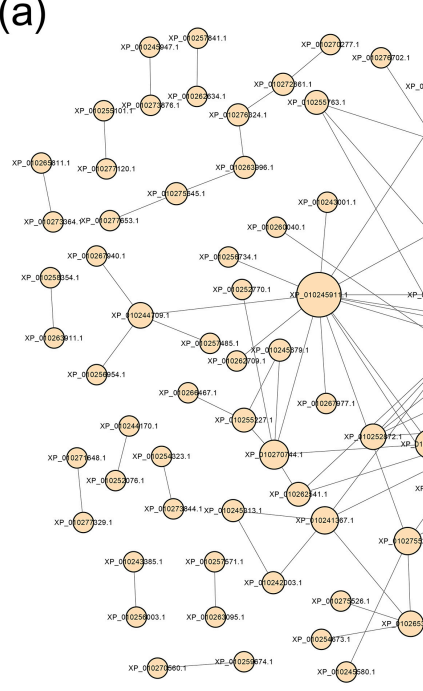

(b)

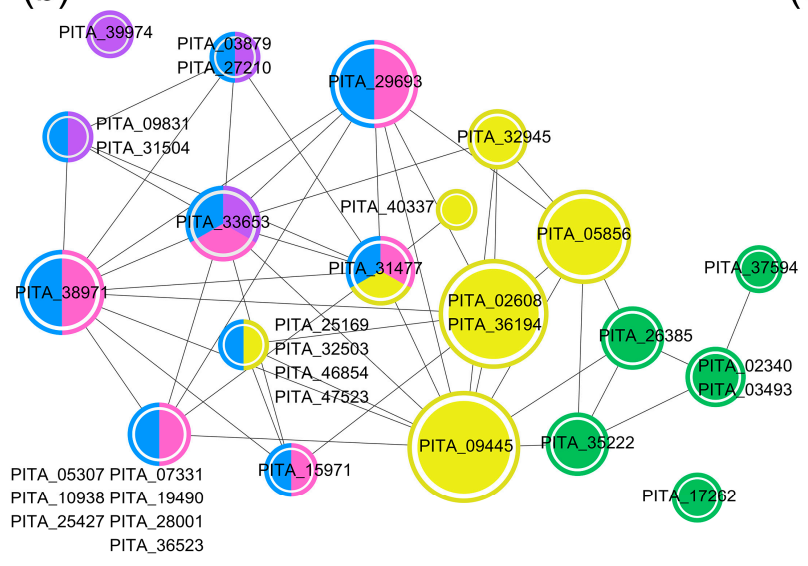

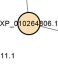

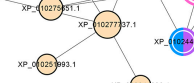

(n)

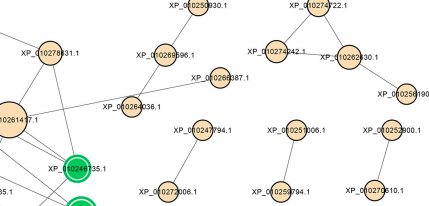

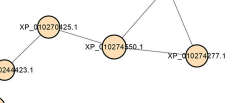

(c)

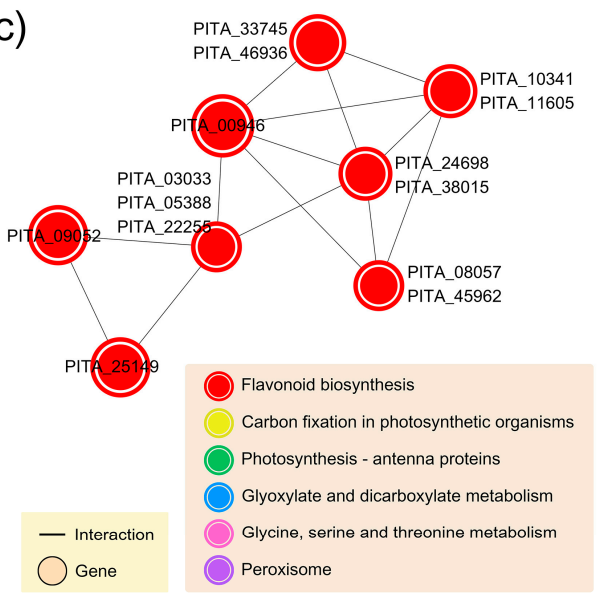

Figure 4. A network of co-expression patterns based on protein-protein interactions. (a) The overall network structure with pathway information. For the co-expression patterns, protein-protein interaction information was collected using Search Tool for the Retrieval of Interacting Genes/Proteins (STRING) v11 and visualised using the Cytoscape tool. A total of 650 upregulated DEGs were used, with interactions showing a combined score of less than 0.5 being filtered out, resulting in 175 nodes and 386 edges. The diameter of the node reflects the number of direct connections to other nodes. Within nodes, KEGG pathways are indicated by different colours (identified in the accompanying key). If genes are associated with more than two KEGG categories, the nodes are divided into the corresponding colours. Two groups of densely connected pathways are displayed as subnetworks. (b) Carbon fixation in photosynthetic organisms; photosynthesis-antenna proteins; glyoxylate and dicarboxylate metabolism; glycine, serine, and threonine metabolism; peroxisome. (c) Flavonoid biosynthesis.

Contrastingly, it was found that genes involved in flavonoid biosynthesis constituted an independent subnetwork, comprising eight nodes of 14 upregulated DEGs and 14 interactions (Figure 4c). Without exception, strong evidence was obtained for each gene in the subnetwork, with an average of 3.4 interactions. Moreover, it was found that some reactions within flavonoid biosynthesis are concentrated and reinforced by those genes at a higher resolution (Figure 5). The expression of constituent genes encoding necessary enzymes was found to be highly induced in response to both ASM and MeSA treatments. In particular, PITA_24698 and PITA_38015 (flavonol synthase) genes showed the highest increases in expression, with average changes of 15.4-fold and 22.1-fold, 
respectively, compared with the control. These genes were found to be commonly associated with the biosynthesis of kaempferol, quercetin, and myricetin. In addition, the reactions yielded different types of flavonoid, some of which are associated with flavone and flavonol biosynthesis (ko00944). The co-expression patterns obtained from the comparative in vivo transcriptomes were confirmed by qPCR analysis. A total of 16 upregulated DEGs were selected from major pathways, including glyoxylate and dicarboxylate metabolism, glycine, serine, and threonine metabolism, peroxisome, and flavonoid biosynthesis. The overall correlation coefficient between RNA-seq data and qPCR data was 0.823 , indicating the reliability of the in vivo transcriptome results (Figure S3).

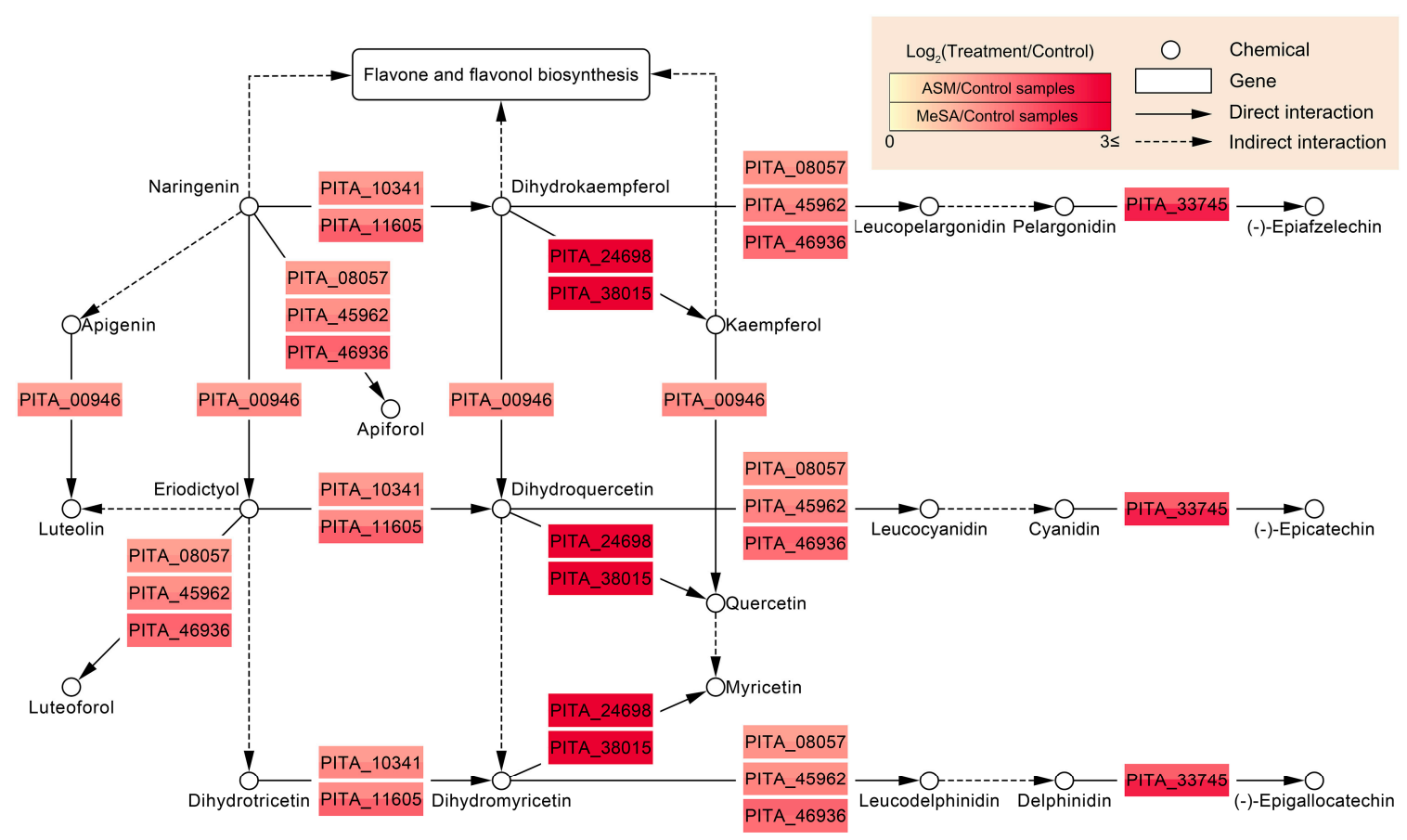

Figure 5. Molecular networks with expression changes in flavonoid biosynthesis. The nodes illustrate the type of molecules as follows: genes (coloured rectangles); biochemicals (circles); cognate pathway (white rectangle). The differences in colour are indicative of the corresponding changes in $\log _{2}$ (treatment/control) values from a minimum of 0 to a maximum of 3 , where a value of 0 indicates the same expression level between treatment and control conditions. The direction of biosynthesis in a pathway is represented by arrows adjacent to the gene names.

\subsection{Functional Systems of ASM- and MeSA-Specific Patterns}

Results relating to the enrichment of DEGs showing unique expression patterns are presented in Figure 3c. Three and six pathways were found to show significant specificity in response to the ASM and MeSA treatments, respectively. Interestingly, genes associated with flavone and flavonol biosynthesis (ko00944) were commonly identified in both unique groups, despite their different genetic composition. Further investigations of the functional details of genes enriched within flavone and flavonol biosynthesis identified differential selection of flavonoid $3^{\prime}, 5^{\prime}$-hydroxylase $\left(\mathrm{F}^{\prime} 5^{\prime} \mathrm{H}\right)$ and flavonoid $3^{\prime}$-monooxygenase $\left(\mathrm{F}^{\prime} \mathrm{H}\right)$ as the key enzymes for flavonol biosynthesis. On the basis of reference to previous studies [61-63], a schematic diagram was produced, depicting flavonol biosynthetic reactions and the expression levels of related genes (Figure 6). The conversion of naringenin to dihydrokaempferol is the initial step in flavonol biosynthesis and it has been shown that the seven genes of $\mathrm{F}^{\prime} 5^{\prime} \mathrm{H}$, which catalyses the conversion of dihydrokaempferol to myricetin, were highly expressed in response to the ASM treatment, whereas these genes showed downregulated or non-significant expression in response to the MeSA treatment. In contrast, F3'H (PITA_36657 
and PITA_39408) associated with quercetin production were identified as upregulated DEGs only in response to MeSA treatment.

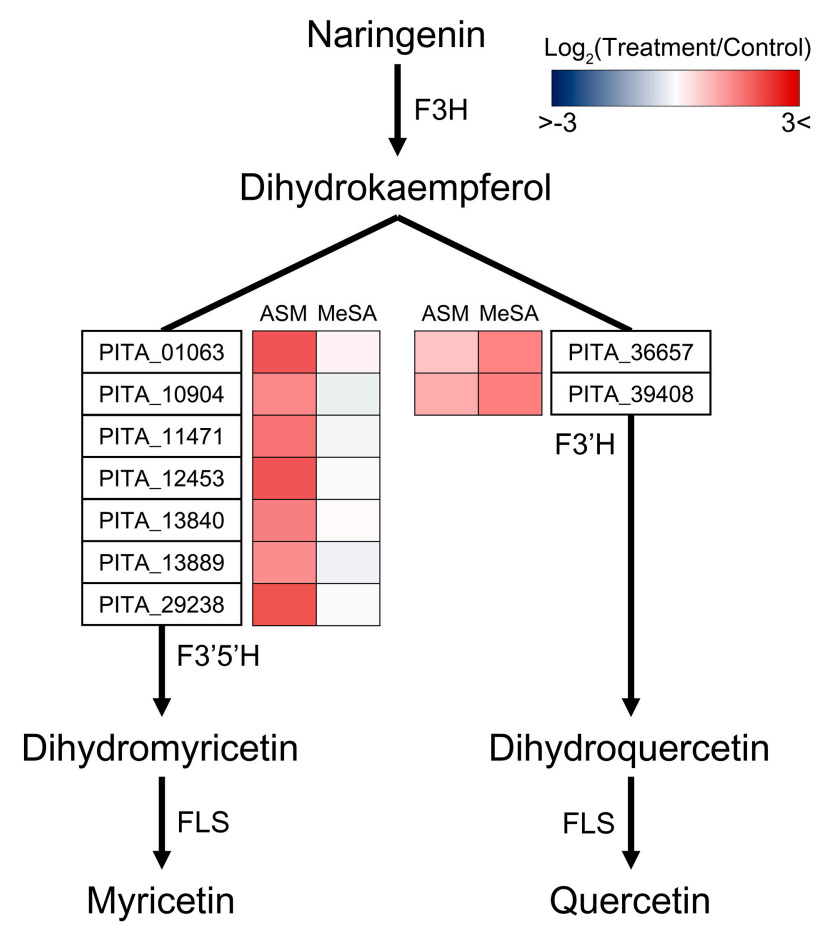

Figure 6. Schematic diagram of flavonol biosynthesis-related genes showing unique expression patterns. The biosynthetic diagram for the production of myricetin and quercetin from naringenin has been modelled. In the acibenzolar-S-methyl (ASM)- and methyl salicylic acid (MeSA)-specific patterns, the expression levels of genes have been calculated according to the $\log _{2}$ (treatment/control) values and are shown as heatmaps. Each coloured cell marked in red indicates upregulation and each cell in blue indicates downregulation. Abbreviations: $\mathrm{F} 3 \mathrm{H}$, naringenin 3-dioxygenase; $\mathrm{F}^{\prime} 5^{\prime} \mathrm{H}$, flavonoid 3' 5' $^{\prime}$-hydroxylase; F3'H, flavonoid 3'-monooxygenase; FLS, flavonol synthase.

The upregulated DEGs were also classified based on GO terms. Among the GO terms assigned to ASM- and MeSA-specific patterns, the 10 most significant results are listed in Table 2; Table 3, respectively (FDR < 0.05). Responses to various stimuli and substrates were mainly enriched with those DEGs showing ASM-specific expression patterns, including negative regulation of response to stimulus (GO:0048585), defence response to fungus, incompatible interaction (GO:0009817), cellular response to indolebutyric acid stimulus (GO:0071366), and response to abscisic acid (GO:0009737) (Table 2). In addition, there were a large number of DEGs related to plant cell walls, including defence response by callose deposition in cell wall (GO:0052544, 26 genes) and regulation of lignin biosynthetic process (GO:1901141, 17 genes). Similar to the DEGs showing ASM-specific expression patterns, the DEGs upregulated in response to MeSA were associated with a number of response GO terms, including defence response to fungus, incompatible interaction (GO:0009817), response to alcohol (GO:0097305), and response to cold (GO:0009409) (Table 3). In particular, defence response to nematode (GO:0002215) and response to nematode (GO:0009624) terms represented a direct association with parasitic nematodes. Taken together, these data indicated that the unique DEGs induced by the two different RISs tend to be functionally consistent but are associated with different reactions and outputs within a similar system of resistance to PWN in pine trees. 
Table 2. Gene ontology (GO) enrichment of acibenzolar-S-methyl-specific patterns.

\begin{tabular}{cccc}
\hline GO ID & Terms & Count & FDR $^{\mathbf{1}}$ \\
\hline GO:0048585 & Negative regulation of response to stimulus & 34 & 0 \\
GO:0006855 & Drug transmembrane transport & 26 & 0 \\
GO:0009817 & Defence response to fungus, incompatible interaction & 26 & 0 \\
GO:0042344 & Indole glucosinolate catabolic process & 26 & 0 \\
GO:0052544 & Defence response by callose deposition in cell wall & 26 & 0 \\
GO:0070574 & Cadmium ion transmembrane transport & 26 & 0 \\
GO:0071366 & Cellular response to indolebutyric acid stimulus & 26 & 0 \\
GO:1901140 & p-Coumaryl alcohol transport & 17 & 0 \\
GO:1901141 & Regulation of lignin biosynthetic process & 17 & 0 \\
GO:0009737 & Response to abscisic acid & 44 & $6.44 \times 10^{-11}$ \\
\hline & ${ }^{1}$ False discovery rate. & &
\end{tabular}

Table 3. Gene ontology (GO) enrichment of methyl salicylic acid-specific patterns.

\begin{tabular}{cccc}
\hline GO ID & Terms & Count & FDR $^{\mathbf{1}}$ \\
\hline GO:0002215 & Defence response to nematode & 9 & $1.27 \times 10^{-7}$ \\
GO:0009624 & Response to nematode & 14 & $1.16 \times 10^{-5}$ \\
GO:0006833 & Water transport & 10 & $2.37 \times 10^{-5}$ \\
GO:0009094 & L-Phenylalanine biosynthetic process & 5 & $2.37 \times 10^{-5}$ \\
GO:0003333 & Amino acid transmembrane transport & 7 & 0.0056 \\
GO:0009817 & Defence response to fungus, incompatible interaction & 8 & 0.0096 \\
GO:0015804 & Neutral amino acid transport & 5 & 0.0096 \\
GO:0051704 & Multi-organism process & 40 & 0.0407 \\
GO:0097305 & Response to alcohol & 25 & 0.0443 \\
GO:0009409 & Response to cold & 14 & 0.0443 \\
\hline
\end{tabular}

${ }^{1}$ False discovery rate.

\section{Discussion}

The present study was conceived with the aim of gaining a better understanding of the dynamic interactions between host pine trees and PWN under conditions of SAR induced by treatment with ASM and MeSA. Comparative in vivo transcriptomes allowed access to key traits involved in direct and indirect defence mechanisms of pine trees among many DEGs that predominantly reflect the stressful conditions caused by PWD. Biological phenotypes are typically complex and often involve the control of dozens to hundreds of genes, changes in the expression of which underlie the adaptive processes of phenotypes in response to a range of environmental and developmental factors [64,65]. The study of in vivo transcriptomes by characterising the complete set of transcripts under physiological conditions can be considered to be indicative of a living organism's blueprint [66]. Given that studies focussing solely on isolated contributary factors often fail to yield meaningful insights into the important elements of biological processes, we designed the present study with a view towards characterising an integrated environment comprising pine hosts, RISs, and PWNs. Simple treatment using RISs is limited to the detection of general genes (termed pathogenesis-related genes) under SAR conditions $[67,68]$, whereas PWN infection in pine trees predominantly reflects the pathogenic mechanisms within dying cells [69]. Consequently, the integrated design of the present study enabled us to assess the sequential stages of RIS treatment and infection, as well as the activation of related genes under conditions of SAR induction, thereby facilitating subsequent analyses of the essential mechanisms underlying the protection against and inhibition of PWN.

As a first line defence response in plants, SAR is an induced immune mechanism that confers a long-lasting state of alert and broad-spectrum non-specific resistance against invaders $[27,29,30]$. On the basis of an in vivo seedling assay, we detected a marked suppression of PWD, revealing the enhanced resistance of pine trees against PWN conferred by SAR induced by treatments with ASM and MeSA (Figure 1). The RISs used in the present study, ASM and MeSA, are functional analogues of SA. 
ASM, which was the first synthetic chemical developed as an SAR elicitor, induces a downstream step in SA accumulation [70,71], whereas MeSA, which is synthesised from plants, is a biologically inactive derivative of SA that is converted to SA in distal tissues [72]. These are structurally stable compounds that are not susceptible to chemical modification, such as rapid glycosylation of SA [33,73,74], and are advantageous in that they can readily penetrate and disperse throughout non-infected plants upon exogenous application [73,75]. Thus, applications of ASM and MeSA can effectively mimic the role of SA. Given the origins and roles of these two RISs, the substantial co-expression patterns obtained following exposure to the two RISs under conditions of PWN infection are perhaps predictable (Figure 3). Such co-expression patterns can reveal important functions of conserved regulatory processes across different conditions, environments, or species [76,77]. During PWN infection, these genes may contribute to fundamental strategies required for the protection and survival of pine hosts.

The most significant results obtained with respect to the co-expression patterns indicated the importance of the photosynthesis system (ko00196), carbon fixation (ko00710), and chlorophyll metabolism (ko00860) (Figure 3). Contrastingly, however, numerous studies have revealed that in response to the establishment of SAR, genes involved in photosynthesis are downregulated to confer a fitness advantage in defence signalling under high disease pressure [78-80]. At the advanced stage of PWD, nematode-induced embolism causes a decrease in leaf water potential from root tissue, and results in the cessation of photosynthesis [81]. Furthermore, parasitic nematodes have a pronounced effect on the uptake of water and nutrient elements required for photosynthesis [82,83]. Hence, we believe that in RIS-treated pines, the genes associated with the photosynthesis system show a relative upregulation compared with that in dying untreated control pines, rather than reflecting a direct response to SAR induced by the ASM and MeSA treatments. Given the essential role of photosynthesis in plant life, and the high sensitivity of photosynthetic processes to different biotic and abiotic stresses, the effective functioning of photosynthesis, as revealed by in vivo transcriptome analysis, is assumed to be indicative of the establishment of an efficacious defence response against nematode infection.

On the basis of our analyses, we noted several systems, including glyoxylate and dicarboxylate metabolism (ko00630), peroxisome (ko04146), and glycine, serine, and threonine metabolism (ko00260), that interact directly with photosynthesis in co-expression patterns (Figure $4 \mathrm{~b}$ ). Interestingly, most upregulated DEGs distributed in the glyoxylate and dicarboxylate metabolism category are associated with the function of the photorespiration module (M00532) in the entire molecular network (Figure S4). As an energy sink for excess ATP and reducing equivalents, photorespiration represents an important alternative pathway for maintaining the growth of $\mathrm{C} 3$ plants such as tobacco, soybeans, and most trees, particularly under stress conditions that lead to reduced rates of photosynthetic reaction $[84,85]$. It has been reported that the generation of reactive oxygen species (ROS) increases rapidly during photosynthesis under drought/water stress conditions [86,87]. Accordingly, given the negative effects of PWN on water uptake, it is assumed that PWD would induce ROS production in pine trees, causing global damage to cellular components. Photorespiration, peroxisome metabolism, and glycine biosynthesis can provide a functional linkage that contributes to protection against ROS-induced damage. Labudda et al. revealed that the number and size of peroxisomes, which contain enzymes required for photorespiration, are increased in the mesophyll cells of leaves in response to parasitic-nematode infection [88]. Compared with water-sufficient conditions, in plants exposed to drought stress, large amounts of glycine are produced, as a consequence of the photorespiration reactions of the elevated numbers of peroxisomes [89]. Notably, glycine is used as a substrate for the production of glutathione, a key component of antioxidant defence systems [90]. Thus, promoting photorespiration under SAR conditions could serve as an alternative strategy for the survival of pine trees infected with PWD, and the functions of the aforementioned linkage systems could explain the essential interactions related to defence against the cellular damage caused by PWN.

Unlike the immune response in animals, plant immunity lacks a complex adaptive system or specialised cells such as lymphocytes (B and T cells) [91,92]. Plants require less complex immune strategies based on fundamental mechanisms, which are, nevertheless, effective against diseases caused 
by various invaders or abiotic stresses [93,94]. Accordingly, it would be reasonable for plants to employ bioactive secondary metabolites such as flavonoids, which act as physiological regulators of defence systems, and there have been studies showing the SA dose-dependent production of flavonoids in plants $[95,96]$. In the present study, we found that under conditions induced by both ASM and MeSA, flavonoid biosynthesis (ko00941) was strongly activated by PWN infection, with the expression levels of associated genes showing an average increase of five-fold (Figure 5). Flavonoids not only function as a secondary antioxidant system by locating and neutralising ROS [97], but also directly and indirectly affect the fitness of nematodes at different life stages [98,99]. In this respect, flavonoids are characterised by nematicidal activity, and Faizi et al. have revealed that treatment of the cyst nematode Heterodera zeae with different concentrations of patuletin, patulitrin, and rutin results in high mortality [100]. Furthermore, several flavonoids with similar structural motifs (fisetin, galangin, isorhamnetin, and morin) have been shown to be effective in killing the root-knot nematode Meloidogyne incognita at the juvenile stages after a 24-h incubation [101]. Flavonoids can also induce quiescence in nematodes by retarding their motility, which provides a temporal window of opportunity for the mobilisation of defence mechanisms in hosts [98]. In this regard, as repellents of $M$. incognita, quercetin and myricetin have been demonstrated to be highly inhibitive of motility [99]. Furthermore, by limiting egg production or controlling the ratio of males to females, flavonoids can affect the levels of nematode fertility [102,103]. Given the pronounced and wide-ranging effects of flavonoids as nematicidal and nemastatic compounds, our results may provide new evidence highlighting the prominent role played by these compounds in the control of PWN infection in pine trees.

Surprisingly, we found that the fundamental defence strategies deployed by pine trees against PWN infection appear to involve different branches of flavonol biosynthesis downstream of flavonoid production. In the biosynthesis of the myricetin and quercetin, the expression patterns of $\mathrm{F}^{\prime} 5^{\prime} \mathrm{H}$ and F3' $\mathrm{H}$ indicated a unique induction in response to only one of the two RISs and showed either non-significant or downregulated expression in response to the other (Figure 6). As representative flavonols, myricetin and quercetin, play an important role in resistance against parasitic nematodes by functioning as nematicidal and nemastatic compounds [99]; however, details of the functional differences between these two flavanols are yet to be ascertained. It has been reported that despite the same SA treatment, wheat plants show different amounts and fluctuations in the production of myricetin and quercetin, depending on the treatment method or plant tissues examined. These observations imply that myricetin and quercetin have independent functions under different conditions. Thus, we hypothesise that the production of different flavonols in response to ASM and MeSA treatment constitutes an important facet of the defensive mechanisms against PWN infection. Furthermore, in the GO analysis of the ASM-specific patterns, we identified the defence response (GO:0052544) and regulation of lignin biosynthesis (GO:1901141) in the plant cell wall as processes that were highly enriched (Table 2). We established that the defence response to nematode (GO:0002215) was the most significantly enriched process associated with the MeSA-specific expression patterns, among which seven genes encode glucan endo-1,3- $\beta$-glucosidases (Table S5), which, as important components of plant cell walls, play roles in defence against pathogens [104,105]. Other genes encoding peroxidases (Table S5) are also involved in the defence mechanisms of plants via cell wall reinforcement [106]. Given that cell wall structure has been implicated as an effective physical barrier against invaders, ASM and MeSA treatments are expected to induce different defence responses based on plant cell wall modification.

\section{Conclusions}

In conclusion, in this study, we performed comparative in vivo transcriptomics in order to characterise the fundamental defence strategies deployed by pine trees against PWN infection. We found that application of the two SAR elicitors, ASM and MeSA, was effective in terms of reducing PWD severity, and induced similar patterns of gene expression associated with plant functions. By overlaying enriched biological pathways onto an interaction network, we demonstrated that the genes showing co-expression patterns constitute a functionally linked system for protection from 
ROS damage caused by PWN infection: peroxisome $\rightarrow$ photorespiration $\rightarrow$ glycine $\rightarrow$ antioxidant glutathione. Furthermore, we observed that flavonoid biosynthesis was highly activated in response to treatment with the two RISs and could act as a countermeasure strategy induced by pine trees to control $\mathrm{PWN}$. Among the genes showing unique patterns of expression in response to SAR, we identified $\mathrm{F}^{\prime} 5^{\prime} \mathrm{H}$ and $\mathrm{F}^{\prime} \mathrm{H}$, which are associated with the production of the flavanols myricetin and quercetin, which are assumed to play important roles in defence mechanisms. To the best of our knowledge, this is the first study to interpret the dynamic interactions between host pine trees and PWN under conditions of SAR induced by exogenous RISs. Our study, underlying the efficacies of ASM and MeSA, could suggest the possibility of effective PWN control agents based on the reinforcement of the development of, and resistance in, pine trees.

Supplementary Materials: The following are available online at http://www.mdpi.com/2073-4425/11/9/1000/s1, Figure S1: Quality assessment of raw reads in the FASTQ format, Figure S2: Pie charts showing functional categories according to BRITE hierarchy analysis, Figure S3: Verification of RNA-seq data by quantitative PCR (qPCR), Figure S4: Molecular networks showing expression changes in the photorespiration module within glyoxylate and dicarboxylate metabolism, Table S1: List of primers for quantitative real-time PCR analysis, Table S2: Overview of RNA-seq read processing, Table S3: List of non-redundant genes in reference genome for the genus Pinus, Table S4: Expression profiling of Pinus densiflora between resistance-inducing substances and untreated control, Table S5: Gene list associated with defence response to nematodes in MeSA-specific patterns.

Author Contributions: Conceptualization, J.-C.K. and Y.-S.S.; methodology, J.P., H.W.J., H.J., J.K., and A.R.P.; validation, J.P., H.W.J., N.K. and G.H.; formal analysis, J.P., H.J. and H.-H.L.; data curation, H.J. and H.-H.L.; writing-original draft preparation, J.P. and H.W.J.; writing-review and editing, J.P., H.J., J.K., N.K., J.-C.K. and Y.-S.S.; project administration, Y.-S.S.; funding acquisition, J.-C.K. All authors have read and agreed to the published version of the manuscript.

Funding: This research was funded by the National Institute of Forest Science (FE0702-2016-07-2019), Korea, and also supported by a grant from the Nakdonggang National Institute of Biological Resources (NNIBR), funded by the Ministry of Environment (NNIBR202002105), Korea.

Acknowledgments: We would like to thank Hokeun Son for his advice regarding the analyses of transcriptome networks.

Conflicts of Interest: The authors declare no conflict of interest. The sponsors had no role in the design, execution, interpretation, or writing of the study.

\section{References}

1. Ghildiyal, S.K.; Gairola, S.; Sharma, C.M. Variation in morphological characters of mycorrhizal seedlings of various provenances of Pinus roxburghii Sargent. N. Y. Sci. J. 2010, 3, 1-8.

2. Semerci, A.; Semerci, H.; Çalişkan, B.; Çiçek, N.; Ekmekçi, Y.; Mencuccini, M. Morphological and physiological responses to drought stress of European provenances of Scots pine. Eur. J. For. Res. 2017, 136, 91-104. [CrossRef]

3. Montwé, D.; Isaac-Renton, M.; Hamann, A.; Spiecker, H. Cold adaptation recorded in tree rings highlights risks associated with climate change and assisted migration. Nat. Commun. 2018, 9, 1-7. [CrossRef] [PubMed]

4. Cañas, R.A.; Canales, J.; Muñoz-Hernández, C.; Granados, J.M.; Ávila, C.; García-Martín, M.L.; Cánovas, F.M. Understanding developmental and adaptive cues in pine through metabolite profiling and co-expression network analysis. J. Exp. Bot. 2015, 66, 3113-3127. [CrossRef] [PubMed]

5. Kwak, C.S.; Moon, S.C.; Lee, M.S. Antioxidant, antimutagenic, and antitumor effects of pine needles (Pinus densiflora). Nutr. Cancer 2006, 56, 162-171. [CrossRef]

6. Kim, Y.B.; Kim, S.M.; Kang, M.K.; Kuzuyama, T.; Lee, J.K.; Park, S.C.; Shin, S.C.; Kim, S.U. Regulation of resin acid synthesis in Pinus densiflora by differential transcription of genes encoding multiple 1-deoxy-d-xylulose 5-phosphate synthase and 1-hydroxy-2-methyl-2-(E)-butenyl 4-diphosphate reductase genes. Tree Physiol. 2009, 29, 737-749. [CrossRef]

7. Toyohara, G.; Fujihara, M. Succession of secondary forests affected by pine wilt disease in western Japan followed on vegetation maps. Appl. Veg. Sci. 1998, 1, 259-266. [CrossRef]

8. Kosaka, H.; Aikawa, T.; Ogura, N.; Tabata, K.; Kiyohara, T. Pine wilt disease caused by the pine wood nematode: The induced resistance of pine trees by the avirulent isolates of nematode. Eur. J. Plant Pathol. 2001, 107, 667-675. [CrossRef] 
9. Kiyohara, T.; Tokushige, Y. Inoculation experiments of a nematode, Bursaphelenchus sp., onto pine trees. J. Jpn. For. Soc. 1971, 53, 210-218.

10. Cheng, H.; Lin, M.; Qian, R. A study on morphological diagnosis and pathogenicity of the pine wood nematode. J. Nanjing Agric. Univ. 1986, 2, 55-59.

11. Yi, C.K.; Byun, B.H.; Park, J.D.; Yang, S.I.; Chang, K.H. First finding of the pine wood nematode, Bursaphelenchus xylophilus (Steiner et Buhrer) Nickle and its insect vector in Korea. Res. Rep. For. Res. Inst. 1989, 38, 141-149.

12. Abelleira, A.; Picoaga, A.; Mansilla, J.P.; Aguin, O. Detection of Bursaphelenchus xylophilus, causal agent of pine wilt disease on Pinus pinaster in Northwestern Spain. Plant Dis. 2011, 95, 776. [CrossRef] [PubMed]

13. Mota, M.M.; Braasch, H.; Bravo, M.A.; Penas, A.C.; Burgermeister, W.; Metge, K.; Sousa, E. First report of Bursaphelenchus xylophilus in Portugal and in Europe. Nematology 1999, 1, 727-734. [CrossRef]

14. MAMiyA, Y. History of pine wilt disease in Japan. J. Nematol. 1988, 20, 219-226. [PubMed]

15. Zhao, L.; Mota, M.; Vieira, P.; Butcher, R.A.; Sun, J. Interspecific communication between pinewood nematode, its insect vector, and associated microbes. Trends Parasitol. 2014, 30, 299-308. [CrossRef]

16. Kulinich, O.; Mota, M.; Vieira, P.; Ryss, A. A synopsis of the genus Bursaphelenchus Fuchs, 1937 (Aphelenchida: Parasitaphelenchidae) with keys to species. Nematology 2005, 7, 393-458. [CrossRef]

17. Ye, W.; Giblin-Davis, R.M.; Braasch, H.; Morris, K.; Thomas, W.K. Phylogenetic relationships among Bursaphelenchus species (Nematoda: Parasitaphelenchidae) inferred from nuclear ribosomal and mitochondrial DNA sequence data. Mol. Phylogenet. Evol. 2007, 43, 1185-1197. [CrossRef]

18. Linit, M.J. Nematode-vector relationships in the pine wilt disease system. J. Nematol. 1988, 20, $227-235$.

19. Fukuda, K. Physiological process of the symptom development and resistance mechanism in pine wilt disease. J. For. Res. 1997, 2, 171-181. [CrossRef]

20. MAMiyA, Y. Initial pathological changes and disease development in pine trees induced by the pine wood nematode, Bursaphelenchus xylophilus. Jpn. J. Phytopathol. 1985, 51, 546-555. [CrossRef]

21. Ichihara, Y.; Fukuda, K.; Suzuki, K. Early symptom development and histological changes associated with migration of Bursaphelenchus xylophilus in seedling tissues of Pinus thunbergii. Plant Dis. 2000, 84, 675-680. [CrossRef] [PubMed]

22. Ishida, K.; Hogetsu, T.; Fukuda, K.; Suzuki, K. Cortical responses in Japanese black pine to attack by the pine wood nematode. Can. J. Bot. 1993, 71, 1399-1405. [CrossRef]

23. Lee, S.; Chung, Y.; Lee, S.; Lee, D.; Choo, H.; Park, C. Toxic effects of some insecticides on the Japanese pine sawyer, Monochamus alternatus. J. Korean For. Soc. 2003.

24. Vicente, C.; Espada, M.; Vieira, P.; Mota, M. Pine wilt disease: A threat to European forestry. Eur. J. Plant Pathol. 2012, 133, 89-99. [CrossRef]

25. Kurinobu, S. Current status of resistance breeding of Japanese pine species to pine wilt disease. For. Sci. Technol. 2008, 4, 51-57. [CrossRef]

26. Park, I.K.; Kim, J.; Lee, S.G.; Shin, S.C. Nematicidal activity of plant essential oils and components from ajowan (Trachyspermum ammi), allspice (Pimenta dioica) and litsea (Litsea cubeba) essential oils against pine wood nematode (Bursaphelenchus xylophilus). J. Nematol. 2007, 39, 275-279.

27. Cao, H.; Li, X.; Dong, X. Generation of broad-spectrum disease resistance by overexpression of an essential regulatory gene in systemic acquired resistance. Proc. Natl. Acad. Sci. USA 1998, 95, 6531-6536. [CrossRef]

28. Romero, A.M.; Ritchie, D.F. Systemic acquired resistance delays race shifts to major resistance genes in bell pepper. Phytopathology 2004, 94, 1376-1382. [CrossRef]

29. Fu, Z.Q.; Dong, X. Systemic acquired resistance: Turning local infection into global defense. Annu. Rev. Plant Biol. 2013, 64, 839-863. [CrossRef]

30. Alexandersson, E.; Mulugeta, T.; Lankinen, Å.; Liljeroth, E.; Andreasson, E. Plant resistance inducers against pathogens in Solanaceae species-From molecular mechanisms to field application. Int. J. Mol. Sci. 2016, 17, 1673. [CrossRef]

31. Mannaa, M.; Han, G.; Jeon, H.W.; Kim, J.; Kim, N.; Park, A.R.; Kim, J.C.; Seo, Y.S. Influence of resistance-inducing chemical elicitors against pine wilt disease on the rhizosphere microbiome. Microorganisms 2020, 8, 884. [CrossRef] [PubMed]

32. Vallad, G.E.; Goodman, R.M. Systemic acquired resistance and induced systemic resistance in conventional agriculture. Crop Sci. 2004, 44, 1920-1934. [CrossRef]

33. Tripathi, D.; Raikhy, G.; Kumar, D. Chemical elicitors of systemic acquired resistance-Salicylic acid and its functional analogs. Curr. Plant Biol. 2019, 17, 48-59. [CrossRef] 
34. Klessig, D.F.; Choi, H.W.; Dempsey, D.A. Systemic acquired resistance and salicylic acid: Past, present, and future. Mol. Plant-Microbe Interact. 2018, 31, 871-888. [CrossRef] [PubMed]

35. Khan, M.I.R.; Fatma, M.; Per, T.S.; Anjum, N.A.; Khan, N.A. Salicylic acid-induced abiotic stress tolerance and underlying mechanisms in plants. Front. Plant Sci. 2015, 6, 462. [CrossRef]

36. Mandlik, A.; Livny, J.; Robins, W.P.; Ritchie, J.M.; Mekalanos, J.J.; Waldor, M.K. RNA-seq-based monitoring of infection-linked changes in Vibrio cholerae gene expression. Cell Host Microbe 2011, 10, 165-174. [CrossRef]

37. Shukla, N.; Yadav, R.; Kaur, P.; Rasmussen, S.; Goel, S.; Agarwal, M.; Jagannath, A.; Gupta, R.; Kumar, A. Transcriptome analysis of root-knot nematode (Meloidogyne incognita)-infected tomato (Solanum lycopersicum) roots reveals complex gene expression profiles and metabolic networks of both host and nematode during susceptible and resistance responses. Mol. Plant Pathol. 2018, 19, 615-633. [CrossRef]

38. Zhou, Y.; Zhao, D.; Shuang, L.; Xiao, D.; Xuan, Y.; Duan, Y.; Chen, L.; Wang, Y.; Liu, X.; Fan, H.; et al. Transcriptome analysis of rice roots in response to root-knot nematode infection. Int. J. Mol. Sci. 2020, 21, 848. [CrossRef]

39. Capoen, W.; Den Herder, J.; Rombauts, S.; De Gussem, J.; De Keyser, A.; Holsters, M.; Goormachtig, S. Comparative transcriptome analysis reveals common and specific tags for root hair and crack-entry invasion in Sesbania rostrata. Plant Physiol. 2007, 144, 1878-1889. [CrossRef]

40. Du, H.; Wang, Y.; Yang, J.; Yang, W. Comparative transcriptome analysis of resistant and susceptible tomato lines in response to infection by Xanthomonas perforans race T3. Front. Plant Sci. 2015, 6, 1173. [CrossRef]

41. Wei, Z.; Zeng, X.; Qin, C.; Wang, Y.; Bai, L.; Xu, Q.; Yuan, H.; Tang, Y.; Nyima, T. Comparative transcriptome analysis revealed genes commonly responsive to varied nitrate stress in leaves of Tibetan hulless barley. Front. Plant Sci. 2016, 7, 1067. [CrossRef] [PubMed]

42. Myers, R.F. Pathogenesis in pine wilt caused by pinewood nematode, Bursaphelenchus xylophilus. J. Nematol. 1988, 20, 244.

43. Xue, Q.; Xiang, Y.; Wu, X.Q.; Li, M.J. Bacterial communities and virulence associated with pine wood nematode Bursaphelenchus xylophilus from different Pinus spp. Int. J. Mol. Sci. 2019, 20, 3342. [CrossRef] [PubMed]

44. Viglierchio, D.R.; Schmitt, R.V. On the methodology of nematode extraction from field samples: Baermann funnel modifications. J. Nematol. 1983, 15, 438-444.

45. Azevedo, H.; Lino-Neto, T.; Tavares, R.M. An improved method for high-quality RNA isolation from needles of adult maritime pine trees. Plant Mol. Biol. Rep. 2003, 21, 333-338. [CrossRef]

46. FastQC: A Quality Control Tool for High Throughput Sequence Data. Available online: https://www. bioinformatics.babraham.ac.uk/projects/fastqc/ (accessed on 26 February 2019).

47. PineRefSeq Database. Available online: https://treegenesdb.org/FTP/Genomes/Pita/ (accessed on 23 April 2019).

48. Zimin, A.V.; Stevens, K.A.; Crepeau, M.W.; Puiu, D.; Wegrzyn, J.L.; Yorke, J.A.; Langley, C.H.; Neale, D.B.; Salzberg, S.L. An improved assembly of the loblolly pine mega-genome using long-read single-molecule sequencing. Gigascience 2017, 6, giw016.

49. FASTX-Toolkit. Available online: http://hannonlab.cshl.edu/fastx_toolkit/ (accessed on 26 February 2019).

50. Li, H.; Durbin, R. Fast and accurate short read alignment with Burrows-Wheeler transform. Bioinformatics 2009, 25, 1754-1760. [CrossRef]

51. Li, H.; Handsaker, B.; Wysoker, A.; Fennell, T.; Ruan, J.; Homer, N.; Marth, G.; Abecasis, G.; Durbin, R. The Sequence Alignment/Map (SAM) format and SAMtools. Bioinformatics 2009, 25, 2078-2079. [CrossRef]

52. Liao, Y.; Smyth, G.K.; Shi, W. featureCounts: An efficient general purpose program for assigning sequence reads to genomic features. Bioinformatics 2014, 30, 923-930. [CrossRef]

53. Mortazavi, A.; Williams, B.A.; McCue, K.; Schaeffer, L.; Wold, B. Mapping and quantifying mammalian transcriptomes by RNA-Seq. Nat. Methods 2008, 5, 621-628. [CrossRef]

54. Wang, L.; Feng, Z.; Wang, X.; Wang, X.; Zhang, X. DEGseq: An R package for identifying differentially expressed genes from RNA-seq data. Bioinformatics 2010, 26, 136-138. [CrossRef] [PubMed]

55. Yang, Y.H.; Dudoit, S.; Luu, P.; Lin, D.M.; Peng, V.; Ngai, J.; Speed, T.P. Normalization for cDNA microarray data: A robust composite method addressing single and multiple slide systematic variation. Nucleic Acids Res. 2002, 30, e15. [CrossRef] [PubMed]

56. Benjamini, Y.; Hochberg, Y. Controlling the false discovery rate: A practical and powerful approach to multiple testing. J. R. Stat. Soc. Ser. B 1995, 57, 289-300. [CrossRef] 
57. Kanehisa, M.; Sato, Y.; Morishima, K. BlastKOALA and GhostKOALA: KEGG tools for functional characterization of genome and metagenome sequences. J. Mol. Biol. 2016, 428, 726-731. [CrossRef]

58. Qureshi, R.; Sacan, A. Weighted set enrichment of gene expression data. BMC Syst. Biol. 2013, 7, S10. [CrossRef]

59. Shannon, P.; Markiel, A.; Ozier, O.; Baliga, N.S.; Wang, J.T.; Ramage, D.; Amin, N.; Schwikowski, B.; Ideker, T. Cytoscape: A software environment for integrated models of biomolecular interaction networks. Genome Res. 2003, 13, 2498-2504. [CrossRef]

60. Szklarczyk, D.; Gable, A.L.; Lyon, D.; Junge, A.; Wyder, S.; Huerta-Cepas, J.; Simonovic, M.; Doncheva, N.T.; Morris, J.H.; Bork, P.; et al. STRING v11: Protein-protein association networks with increased coverage, supporting functional discovery in genome-wide experimental datasets. Nucleic Acids Res. 2019, 47, D607-D613. [CrossRef]

61. Jeong, S.T.; Goto-Yamamoto, N.; Hashizume, K.; Esaka, M. Expression of the flavonoid 3'-hydroxylase and flavonoid $3^{\prime}, 5^{\prime}$-hydroxylase genes and flavonoid composition in grape (Vitis vinifera). Plant Sci. 2006, 170, 61-69. [CrossRef]

62. Lim, W.; Li, J. Synergetic effect of the Onion CHI gene on the PAP1 regulatory gene for enhancing the flavonoid profile of tomato skin. Sci. Rep. 2017, 7, 1-12. [CrossRef]

63. Jeewani, D.C.; Hua, W.Z. Recent advances in anthocyanin biosynthesis in colored wheat. Res. J. Biotechnol. 2017, 12, 6.

64. Pancaldi, V.; Schubert, F.; Bähler, J. Meta-analysis of genome regulation and expression variability across hundreds of environmental and genetic perturbations in fission yeast. Mol. Biosyst. 2010, 6, 543-552. [CrossRef] [PubMed]

65. Harrison, P.W.; Wright, A.E.; Mank, J.E. The evolution of gene expression and the transcriptome-phenotype relationship. Semin. Cell Dev. Biol. 2012, 23, 222-229. [CrossRef] [PubMed]

66. Wang, Z.; Gerstein, M.; Snyder, M. RNA-Seq: A revolutionary tool for transcriptomics. Nat. Rev. Genet. 2009, 10, 57-63. [CrossRef] [PubMed]

67. Luo, J.; Xia, W.; Cao, P.; Xiao, Z.; Zhang, Y.; Liu, M.; Zhan, C.; Wang, N. Integrated transcriptome analysis reveals plant hormones jasmonic acid and salicylic acid coordinate growth and defense responses upon fungal infection in poplar. Biomolecules 2019, 9, 12. [CrossRef] [PubMed]

68. Wang, F.; Zhi, J.; Zhang, Z.; Wang, L.; Suo, Y.; Xie, C.; Li, M.; Zhang, B.; Du, J.; Gu, L.; et al. Transcriptome analysis of salicylic acid treatment in Rehmannia glutinosa hairy roots using RNA-seq technique for identification of genes involved in acteoside biosynthesis. Front. Plant Sci. 2017, 8, 787. [CrossRef]

69. Gaspar, D.; Trindade, C.; Usié, A.; Meireles, B.; Fortes, A.M.; Guimarães, J.B.; Simões, F.; Costa, R.L.; Ramos, A.M. Comparative transcriptomic response of two Pinus species to infection with the pine wood nematode Bursaphelenchus xylophilus. Forests 2020, 11, 204. [CrossRef]

70. Bektas, Y.; Eulgem, T. Synthetic plant defense elicitors. Front. Plant Sci. 2015, 5, 1-9. [CrossRef]

71. Kunz, W.; Schurter, R.; Maetzke, T. The chemistry of benzothiadiazole plant activators. Pestic. Sci. 1997, 50, 275-282. [CrossRef]

72. Park, S.W.; Kaimoyo, E.; Kumar, D.; Mosher, S.; Klessig, D.F. Methyl salicylate is a critical mobile signal for plant systemic acquired resistance. Science (80-) 2007, 318, 113-116. [CrossRef]

73. Shulaev, V.; Silverman, P.; Raskin, I. Airborne signalling by methyl salicylate in plant pathogen resistance. Nature 1997, 385, 718-721. [CrossRef]

74. Kunwar, S.; Paret, M.L.; Freeman, J.H.; Ritchie, L.; Olson, S.M.; Colee, J.; Jones, J.B. Foliar applications of acibenzolar-S-methyl negatively affect the yield of grafted tomatoes in fields infested with Ralstonia solanacearum. Plant Dis. 2017, 101, 890-894. [CrossRef] [PubMed]

75. Gao, Q.M.; Zhu, S.; Kachroo, P.; Kachroo, A. Signal regulators of systemic acquired resistance. Front. Plant Sci. 2015, 6, 228. [CrossRef]

76. Gerstein, M.B.; Rozowsky, J.; Yan, K.K.; Wang, D.; Cheng, C.; Brown, J.B.; Davis, C.A.; Hillier, L.; Sisu, C.; Li, J.J.; et al. Comparative analysis of the transcriptome across distant species. Nature 2014, 512, 445-448. [CrossRef]

77. Chan, E.T.; Quon, G.T.; Chua, G.; Babak, T.; Trochesset, M.; Zirngibl, R.A.; Aubin, J.; Ratcliffe, M.J.; Wilde, A.; Brudno, M.; et al. Conservation of core gene expression in vertebrate tissues. J. Biol. 2009, 8, 33. [CrossRef] [PubMed] 
78. Bernsdorff, F.; Döring, A.C.; Gruner, K.; Schuck, S.; Bräutigam, A.; Zeier, J. Pipecolic acid orchestrates plant systemic acquired resistance and defense priming via salicylic acid-dependent and -independent pathways. Plant Cell 2016, 28, 102-129. [CrossRef] [PubMed]

79. Traw, M.B.; Kniskern, J.M.; Bergelson, J. SAR increases fitness of Arabidopsis thaliana in the presence of natural bacterial pathogens. Evol. Int. J. Org. Evol. 2007, 61, 2444-2449. [CrossRef]

80. Rivas-San Vicente, M.; Plasencia, J. Salicylic acid beyond defence: Its role in plant growth and development. J. Exp. Bot. 2011, 62, 3321-3338. [CrossRef]

81. Fukuda, K.; Utsuzawa, S.; Sakaue, D. Correlation between acoustic emission, water status and xylem embolism in pine wilt disease. Tree Physiol. 2007, 27, 969-976. [CrossRef]

82. Melakeberhan, H.; Toivonen, P.; Vidaver, W.; Webster, J.; Dube, S. Effect of Bursaphelenchus xylophilus on the water potential and water-splitting complex of photosystem II of Pinus sylvestris seedlings. Physiol. Mol. Plant Pathol. 1991, 38, 83-91. [CrossRef]

83. Melakeberhan, H.; Brooke, R.; Webster, J.; D'Auria, J. The influence of Meloidogyne incognita on the growth, physiology and nutrient content of Phaseolus vulgaris. Physiol. Plant Pathol. 1985, 26, 259-268. [CrossRef]

84. Wingler, A.; Lea, P.J.; Quick, W.P.; Leegood, R.C. Photorespiration: Metabolic pathways and their role in stress protection. Philos. Trans. R. Soc. London. Ser. B Biol. Sci. 2000, 355, 1517-1529. [CrossRef] [PubMed]

85. Foyer, C.H.; Bloom, A.J.; Queval, G.; Noctor, G. Photorespiratory metabolism: Genes, mutants, energetics, and redox signaling. Annu. Rev. Plant Biol. 2009, 60, 455-484. [CrossRef] [PubMed]

86. Loggini, B.; Scartazza, A.; Brugnoli, E.; Navari-Izzo, F. Antioxidative defense system, pigment composition, and photosynthetic efficiency in two wheat cultivars subjected to drought. Plant Physiol. 1999, 119, 1100. [CrossRef] [PubMed]

87. Cruz De Carvalho, M.H. Drought stress and reactive oxygen species: Production, scavenging and signaling. Plant Signal. Behav. 2008, 3, 156-165. [CrossRef]

88. Labudda, M.; Różańska, E.; Czarnocka, W.; Sobczak, M.; Dzik, J.M. Systemic changes in photosynthesis and reactive oxygen species homeostasis in shoots of Arabidopsis thaliana infected with the beet cyst nematode Heterodera schachtii. Mol. Plant Pathol. 2018, 19, 1690-1704. [CrossRef]

89. Sicher, R.C.; Barnaby, J.Y. Impact of carbon dioxide enrichment on the responses of maize leaf transcripts and metabolites to water stress. Physiol. Plant. 2012, 144, 238-253. [CrossRef]

90. Noctor, G.; Arisi, A.C.M.; Jouanin, L.; Foyer, C.H. Photorespiratory glycine enhances glutathione accumulation in both the chloroplastic and cytosolic compartments. J. Exp. Bot. 1999, 50, 1157-1167. [CrossRef]

91. Koda, Y.; Takahashi, K.; Kikuta, Y.; Greulich, F.; Toshima, H.; Ichihara, A. Similarities of the biological activities of coronatine and coronafacic acid to those of jasmonic acid. Phytochemistry 1996, 41, 93-96. [CrossRef]

92. Maekawa, T.; Kufer, T.A.; Schulze-Lefert, P. NLR functions in plant and animal immune systems: So far and yet so close. Nat. Immunol. 2011, 12, 817. [CrossRef]

93. Navarro, L.; Zipfel, C.; Rowland, O.; Keller, I.; Robatzek, S.; Boller, T.; Jones, J.D.G. The transcriptional innate immune response to flg22. Interplay and overlap with Avr gene-dependent defense responses and bacterial pathogenesis. Plant Physiol. 2004, 135, 1113-1128. [CrossRef]

94. Tao, Y.; Xie, Z.; Chen, W.; Glazebrook, J.; Chang, H.S.; Han, B.; Zhu, T.; Zou, G.; Katagiri, F. Quantitative nature of Arabidopsis responses during compatible and incompatible interactions with the bacterial pathogen Pseudomonas syringae. Plant Cell 2003, 15, 317-330. [CrossRef] [PubMed]

95. Preciado-Rangel, P.; Reyes-Pérez, J.; Ramírez-Rodríguez, S.; Salas-Pérez, L.; Fortis-Hernández, M.; Murillo-Amador, B.; Troyo-Diéguez, E. Foliar aspersion of salicylic acid improves phenolic and flavonoid compounds, and also the fruit yield in cucumber (Cucumis sativus L.). Plants 2019, 8, 44. [CrossRef] [PubMed]

96. Li, X.; Zhang, L.P.; Zhang, L.; Yan, P.; Ahammed, G.; Han, W.Y. Methyl salicylate enhances flavonoid biosynthesis in tea leaves by stimulating the phenylpropanoid pathway. Molecules 2019, 24, 362. [CrossRef] [PubMed]

97. Agati, G.; Azzarello, E.; Pollastri, S.; Tattini, M. Flavonoids as antioxidants in plants: Location and functional significance. Plant Sci. 2012, 196, 67-76. [CrossRef] [PubMed]

98. Chin, S.; Behm, C.A.; Mathesius, U. Functions of flavonoids in plant-nematode interactions. Plants 2018, 7, 85. [CrossRef]

99. Wuyts, N.; Swennen, R.; De Waele, D. Effects of plant phenylpropanoid pathway products and selected terpenoids and alkaloids on the behaviour of the plant-parasitic nematodes Radopholus similis, Pratylenchus penetrans and Meloidogyne incognita. Nematology 2006, 8, 89-101. [CrossRef] 
100. Faizi, S.; Fayyaz, S.; Bano, S.; Yawar Iqbal, E.; Lubna, L.; Siddiqi, H.; Naz, A. Isolation of nematicidal compounds from Tagetes patula L. yellow flowers: Structure-activity relationship studies against cyst nematode Heterodera zeae infective stage larvae. J. Agric. Food Chem. 2011, 59, 9080-9093. [CrossRef]

101. Bano, S.; Iqbal, E.Y.; Lubna; Zik-ur-Rehman, S.; Fayyaz, S.; Faizi, S. Nematicidal activity of flavonoids with structure activity relationship (SAR) studies against root knot nematode Meloidogyne incognita. Eur. J. Plant Pathol. 2020, 157, 299-309. [CrossRef]

102. Grundler, F.; Betka, M.; Wyss, U. Influence of changes in the nurse cell system (syncytium) on sex determination and development of the cyst nematode Heterodera schachtii: Total amounts of proteins and amino acids. Phytopathology 1991, 81, 70-74. [CrossRef]

103. Jones, J.T.; Furlanetto, C.; Phillips, M.S. The role of flavonoids produced in response to cyst nematode infection of Arabidopsis thaliana. Nematology 2007, 9, 671-677. [CrossRef]

104. Uzal, E.N.; Gómez-Ros, L.V.; Hernández, J.A.; Pedreño, M.A.; Cuello, J.; Ros Barceló, A. Analysis of the soluble cell wall proteome of gymnosperms. J. Plant Physiol. 2009, 166, 831-843. [CrossRef] [PubMed]

105. Yeoh, K.A.; Othman, A.; Meon, S.; Abdullah, F.; Ho, C.L. Sequence analysis and gene expression of putative exo- and endo-glucanases from oil palm (Elaeis guineensis) during fungal infection. J. Plant Physiol. 2012, 169, 1565-1570. [CrossRef] [PubMed]

106. Aryal, S.K.; Davis, R.F.; Stevenson, K.L.; Timper, P.; Ji, P. Influence of infection of cotton by Rotylenchulus reniformis and Meloidogyne incognita on the production of enzymes involved in systemic acquired resistance. J. Nematol. 2011, 43, 152-159. [PubMed]

(C) 2020 by the authors. Licensee MDPI, Basel, Switzerland. This article is an open access article distributed under the terms and conditions of the Creative Commons Attribution (CC BY) license (http://creativecommons.org/licenses/by/4.0/). 